\title{
Decrypting the Role of Systemic Illnesses in Developmental Defects of Enamel
}

\author{
Sanjeev Singh ${ }^{1}$, Mrinalini Rathore $^{2}{ }^{\odot}$, Aditi Kapur $^{3}$
}

\begin{abstract}
The development of dental hard tissues involves a very intricate mechanism beginning in utero and continuing up to the first few years of life. The developmental processes involved at the cellular level are extremely sensitive to genetic and environmental factors. Any systemic disturbance during this period is thus likely to affect the developing dentition manifesting as a wide spectrum of defects in the enamel, dentin, or overall tooth morphology. Clinically, these often present as discoloration causing aesthetic concerns, tooth sensitivity, increased caries susceptibility, the risk for pulpal involvement, and its sequelae. Various authors have attempted to identify the range of environmental stressors that lead to such defects, but no definite etiology has yet been established. Further research is warranted to better understand these entities, improving their predictability and thus, aiding in timely diagnosis and successful treatment of the defects.

Keywords: Dental, Developmental defects, Enamel, Hard tissue, Hypomineralization, Hypoplasia.

Journal of Postgraduate Medicine, Education and Research (2022): 10.5005/jp-journals-10028-1564
\end{abstract}

\section{INTRODUCTION}

Normal dentition develops from the dental lamina originating from a string of epithelial cells in the oral ectoderm during the initial months of embryonic development. By the end of the seventh month in utero, the development of all tooth buds is complete and the formation of enamel and dentine begins. The development of the permanent incisors and premolars is initiated in the fifth month in utero and lasts to the tenth month after birth with the development of the permanent molars continuing through the first years of life but enamel formation continues till $4-5$ years for incisors and $2-3$ years for a molar. ${ }^{1}$ The epithelial-mesenchymal interaction is a normal and necessary event during odontogenesis, being susceptible to errors due to the intricacy of the molecular processes involved. ${ }^{2}$ The developing tooth bud has been shown to be sensitive to a wide range of systemic disturbances and, enamel particularly, is generally unable to recover once it is damaged (Table 1). Particularly sensitive periods are 4-6 months in utero extending to the first 3 years postbirth. This period corresponds to the differentiation and calcification stages when histodifferentiation and morphodifferentiation of dental hard tissues occurs. Any insult during this period may potentially result in developmental defects of enamel.

The defects may affect one surface of the enamel or be evident throughout its full thickness and maybe symmetrical or asymmetrical across the midline of the dentition. Furthermore, defects such as differences from the normal appearance, color, and texture of the tooth, altered translucency, and pitting, grooving, or missing enamel may result from very different causes including hypomineralization, growth reduction, hypoplasia, or dysplasias and drug treatments. The plethora of clinical entities that may arise out of such aberrations and the plausible etiological factors associated with them have been briefly reviewed.

\section{Etiology}

It is essential that the etiology be determined to allow timely risk assessment and diagnosis, intervention, and if possible, prevention of risk factors. ${ }^{3}$ Disturbances to amelogenesis, most likely of systemic \begin{tabular}{l}
\hline 1,20ral Health Sciences Centre, Postgraduate Institute of Medical \\
Education and Research, Chandigarh, India \\
${ }^{3}$ Pedodontics and Preventive Dentistry Oral Health Sciences \\
Center Postgraduate Institute of Medical Education and Research, \\
Chandigarh, India
\end{tabular}

Corresponding Author: Sanjeev Singh, Oral Health Sciences Centre, Postgraduate Institute of Medical Education and Research, Chandigarh, India, Phone: +91 9780554348, e-mail: san.bajaj88@gmail.com

How to cite this article: Singh S, Rathore M, Kapur A. Decrypting the Role of Systemic Illnesses in Developmental Defects of Enamel. J Postgrad Med Edu Res 2022;56(1):21-28.

Source of support: Nil

Conflict of interest: None

origin, during tooth development, will likely cause developmental defects of enamel (DDE). ${ }^{4}$ Several authors have studied and reported the etiological factors for these defects ranging from genetic influences, systemic diseases, environmental stressors as well as any trauma during the span of dental development. The various etiological factors and their effects on the developing dentition have been tabulated and illustrated in Table 2 and Flowchart 1. As varied as their possible etiological factors are, the defects arising from them also present as a wide spectrum of dental abnormalities, some of which have been elaborated on further.

\section{Developmental Defects of Enamel}

The DDE includes a wide range of entities viz. enamel hypoplasia, dental fluorosis, amelogenesis and dentinogenesis imperfect (DI), tooth discoloration due to tetracycline staining, hypomineralized enamel, or any other diffuse hypoplastic lesions etc. The various terminologies associated with this spectrum of defects and also the differentiation between qualitative and quantitative enamel defects have been tabulated in Table 2 .

\section{Enamel Hypoplasia (Fig. 1A)}

It is a quantitative defect resulting in a reduced localized thickness of enamel. On the other hand, hypomineralization is a

(c) The Author(s). 2022 Open Access This article is distributed under the terms of the Creative Commons Attribution 4.0 International License (https://creativecommons. org/licenses/by-nc/4.0/), which permits unrestricted use, distribution, and non-commercial reproduction in any medium, provided you give appropriate credit to the original author(s) and the source, provide a link to the Creative Commons license, and indicate if changes were made. The Creative Commons Public Domain Dedication waiver (http://creativecommons.org/publicdomain/zero/1.0/) applies to the data made available in this article, unless otherwise stated. 
qualitative defect affecting the translucency of the enamel. The developmental difference between these two entities mainly lies in the stage of enamel formation (amelogenesis) at which the insult to the ameloblast (enamel forming cells) would have occurred. To be precise, if the insult had occurred at the secretory stage of amelogenesis, it would result in enamel hypoplasia, manifesting clinically as a thin enamel with pits and grooves over the surface.

Sometimes, clinicians may mistake these defects as white spot lesions which are an entirely different entity. White spot lesions are an incipient carious lesion, most commonly present at plaque retentive zones like gingival margin, occlusal pits and fissures, and cervical enamel is being the commonly affected site (Fig. 1B).

\section{Molar Incisor Hypomineralization (Fig. 2)}

Enamel Hypomineralization results from insults to the ameloblasts that occur during the maturation stage of amelogenesis, manifesting as established entities like deciduous molar hypomineralization $(\mathrm{DMH})$ or molar incisor hypomineralization $(\mathrm{MIH})$. The enamel hypoplastic defect is visible from the time the tooth erupts whereas enamel hypomineralization does not usually show the reduced thickness of enamel and thus is not identifiable at the time of tooth eruption. However, as the enamel in the case of $\mathrm{DMH} / \mathrm{MIH}$ is poorly calcified, it soon undergoes a structural loss as a result of masticatory stresses resulting in posteruptive breakdown. Thus, it is considered that in hypoplasia the breakdown is preeruptive unlike $\mathrm{DMH} / \mathrm{MIH}$ in which it is posteruptive (Fig. 2). Moreover, the borders of the deficient enamel in a hypoplastic tooth are smooth while in hypomineralized tooth the broken-down enamel borders are irregular.

\section{Dental Fluorosis (Fig. 3)}

Dental fluorosis results from the deposition of fluoride ions in the developing enamel microstructure due to systemic exposure to excessive fluoride during the first 8 years of life. The enamel opacities seen with this entity are diffuse in contrast to the well-demarcated opacities seen in hypomineralized enamel defects. Furthermore, the fluorosed enamel is usually resistant to caries in comparison with hypomineralized/hypoplastic enamel which has been found to exhibit high caries susceptibility. Another distinctive feature of fluorosis is the homogeneous distribution of the defect.

\section{Amelogenesis Imperfecta (Fig. 4)}

Amelogenesis imperfecta (Al) is a hereditary enamel defect that affects all the existing teeth in both the primary and permanent

Table 1: Various types of risk factors and their effects on developing teeth

\begin{tabular}{|c|c|c|}
\hline Extent of defects & Conditions & Effect on developing teeth \\
\hline Generalized enamel defects & $\begin{array}{l}\text { Inherited conditions } \\
\text { - } \text { Amelogenesis imperfecta } \\
\text { - } \text { Dentinogenesis imperfecta } \\
\text { Maternal conditions during pregnancy } \\
\text { Infections } \\
\text { - Cytomegalovirus } \\
\text { - Rubella } \\
\text { - Syphilis } \\
\text { P HIV } \\
\text { Pregnancy-related events } \\
\text { - Toxemia of pregnancy } \\
\text { - Breech positioning } \\
\text { - Prolonged/difficult delivery } \\
\text { Maternal systemic illness and health behavior } \\
\text { - Diabetes mellitus } \\
\text { - Hydantoin intake } \\
\text { - Alcohol abuse } \\
\text { - Tetracycline } \\
\text { Nutritional deficiency } \\
\text { - Vitamin D deficiency } \\
\text { Birth trauma } \\
\text { Preterm birth } \\
\text { Isolated cleft lip and palate } \\
\text { Renal and liver conditions e.g., renal failure, biliary atresia } \\
\text { Celiac disease } \\
\text { Endocrine disorders } \\
\text { - Hypocalcemia } \\
\text { - Hypoglycemia } \\
\text { Bacterial, viral, and fungal infections } \\
\text { Chemical and toxins } \\
\text { Other systemic conditions } \\
\text {. }\end{array}$ & $\begin{array}{l}\text { Enamel hypoplasia } \\
\text { Cleft lip/palate } \\
\text { Maxillary hypoplasia } \\
\text { Tooth staining } \\
\text { Cleft lip/palate } \\
\text { Hypoplasia/hypomineralized enamel }\end{array}$ \\
\hline Localized factors & $\begin{array}{l}\text { Trauma } \\
\text { Radiation } \\
\text { Local infection }\end{array}$ & $\begin{array}{l}\text { Arrested root development } \\
\text { Caries, arrested root development }\end{array}$ \\
\hline
\end{tabular}


Table 2: Differentiation between the hypoplastic and hypomineralized developmental defects of enamel

\begin{tabular}{|c|c|c|}
\hline \multirow[b]{2}{*}{ Cause/presentation } & \multicolumn{2}{|c|}{ Developmental defects of enamel } \\
\hline & Quantitative defects & Qualitative defects \\
\hline Cause & Disruption in the formation of matrix & Enamel mineralization gets altered \\
\hline Clinical presentation & $\begin{array}{l}\text { Pits/grooves } \\
\text { Thin or missing enamel } \\
\text { Yellow, gray, or brown discoloration with/ } \\
\text { without loss of enamel }\end{array}$ & $\begin{array}{l}\text { Altered translucency/ enamel opacities which could } \\
\text { be diffuse or localized and color ranges from white, } \\
\text { yellow, or brown } \\
\text { White or yellow subsurface opacities }\end{array}$ \\
\hline Implicated phase of amelogenesis & Secretory & Early maturative \\
\hline Enamel & Thin & Normal thickness with altered translucency \\
\hline Posteruptive breakdown (PEB) & - & + \\
\hline Outline of defects & Smooth & Irregular with sharp boundaries \\
\hline \multicolumn{3}{|c|}{ Terms and definitions relevant to developmental defects of enamel } \\
\hline Term & \multicolumn{2}{|l|}{ Definition } \\
\hline Opacity & \multicolumn{2}{|l|}{ Altered translucency } \\
\hline Diffuse opacity & \multicolumn{2}{|c|}{ Altered translucency distributed over a relatively large area } \\
\hline Demarcated opacity & \multicolumn{2}{|c|}{ Altered translucency confined to a relatively small area } \\
\hline Hypoplasia & \multicolumn{2}{|c|}{ Reduced quantity of formed tissue } \\
\hline Hypomineralization/hypocalcification & \multicolumn{2}{|l|}{ Reduced deposition of mineral } \\
\hline Hypomaturation & \multicolumn{2}{|c|}{ Reduce mineral deposition at the maturation stage of amelogenesis } \\
\hline
\end{tabular}

Flowchart 1: Schematic overview showing an approach to the collection of data and classification of findings related to developmental disturbances of the dental hard tissue (Ivar Espelid et al.)

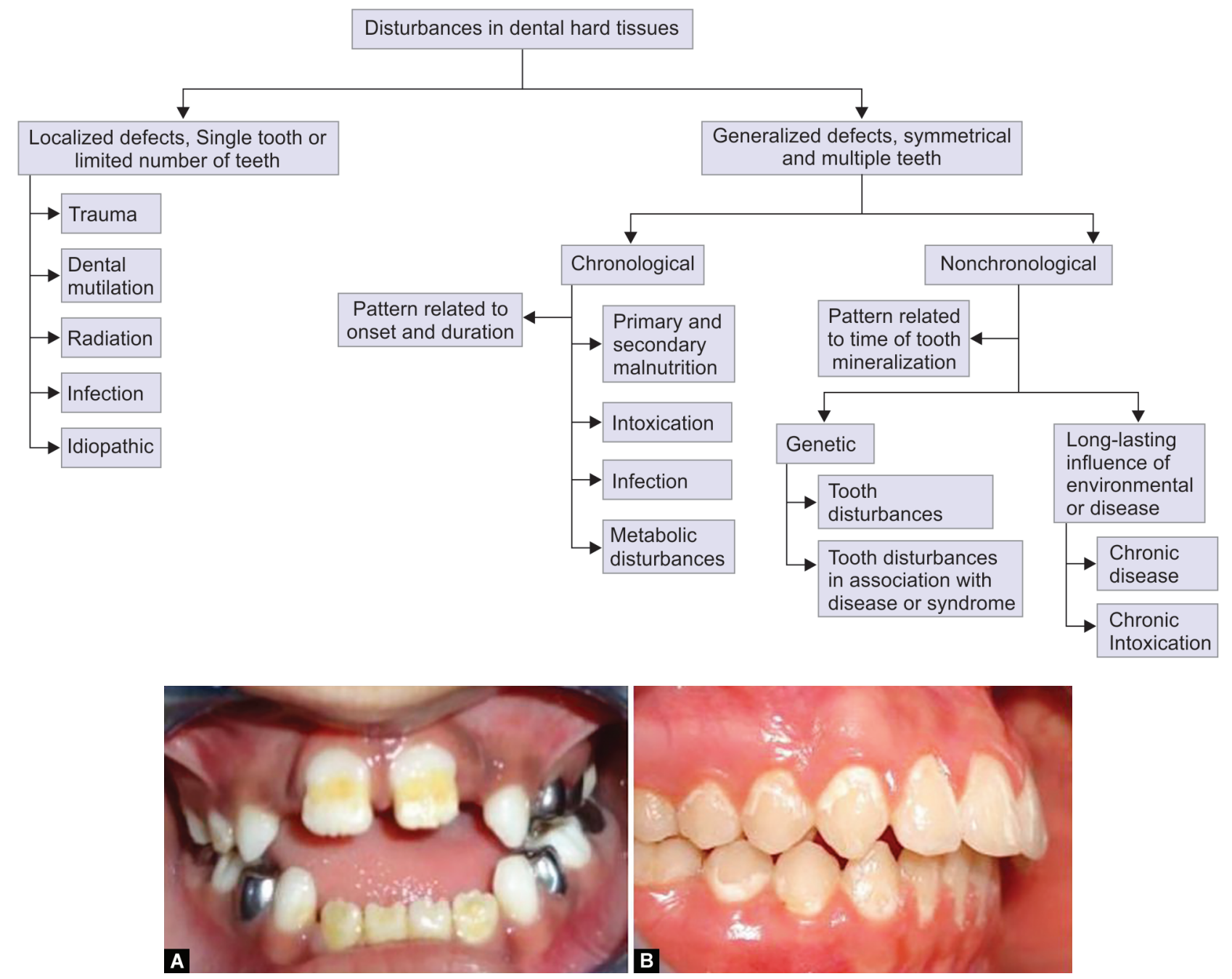

Figs $1 \mathrm{~A}$ and B: (A) Enamel hypoplasia; (B) White spot lesion 
dentition. Although Al primarily affects enamel formation, other dental manifestations may also coexist, including high prevalence of dental impaction, accelerated dental development, congenitally missing teeth, resorption of the crown and/or root, pulp obliteration, and other associated abnormalities.

\section{Dentinogenesis Imperfecta (Fig. 5)}

Dentinogenesis imperfecta (DI) is a hereditary developmental defect in dentin due to a mutation in the dentin sialoprotein gene which is responsible for the coding of major proteins involved in dentin formation. ${ }^{5}$ Clinically, both dentitions are affected. The color of the affected teeth may vary from brown to blue, with an opalescent appearance. Additionally, the enamel may have hypoplastic or hypomineralized defects in about one-third of the patients and tends to crack away from the defective dentin. The exposed dentin may undergo severe and rapid attrition. ${ }^{6}$ Its prevalence is reported to be 1/6000-1/8000 for nonsyndromic and $1 / 100,000$ for syndromic cases. ${ }^{7,8}$ The diagnosis and treatment of $\mathrm{DI}$ poses a challenge due to the clinical presentation being highly diverse and all available treatment strategies lacking strong supporting evidence.

Besides osteogenesis imperfecta, DI type I can also be seen in other conditions such as Ehlers-Danlos and Goldblatt syndromes. ${ }^{3,9}$

\section{Dentin Dysplasia}

It is a rare disturbance of dentin formation characterized by the normal crown with short roots in primary and permanent dentitions. Clinically these teeth may appear sound, but radiographically their altered pulpal and root morphology becomes evident in the form of obliterated pulp chambers and short, blunted roots often with a periapical radiolucency. Broadly, two types have been recognized based on their clinical and radiographic characteristics. Type I (radicular) dentin dysplasia affects both, primary and permanent dentitions such that the teeth have a seemingly sound appearance but exhibit extreme mobility and undergo premature exfoliation. Type II (coronal) dentin dysplasia also affects both dentitions. The affected primary teeth take on a bluish or amber discoloration and show total pulp obliteration, while the permanent dentition appears normal but radiographically their pulp chamber has a characteristic thistle-tube appearance with multiple pulp stones.

\section{Molar Root Incisor Malformation}

A new type of nonhereditary dental abnormality affecting only first permanent molars was reported by Witt et al. ${ }^{10}$ The defects were found to be radiographically similar to dentin dysplasia type I b (DD 1b) which is characterized by a narrow slit-like pulp chamber, shortened malformed roots. In 2014, Lee et al. published 12 cases with similar dental findings which they named Molar Incisor malformation. ${ }^{11}$ Wright et al. have advocated the use of the term Molar Root Incisor Malformation (MRIM) instead of molar incisor malformation in order to avoid confusion with other similar terminology used for hypomineralized molars viz. MIH. ${ }^{12}$ It is a rare, recently described dental abnormality typically discovered in pediatric patients that almost always affects the first permanent molars and may present with sudden periodontal abscess.

\section{Importance of early Diagnosis and Interception}

Early diagnosis and preventive care are essential for the successful management of DDE. Children who have a family history of defects like Amelogenesis imperfecta, DI, hypophosphatemia, MIH, etc, or children with medical history in the perinatal and postnatal stage up to three to four years of age should be screened early for possible dental problems by the prenatal and postnatal health care professionals who can further initiate referrals to the pediatric

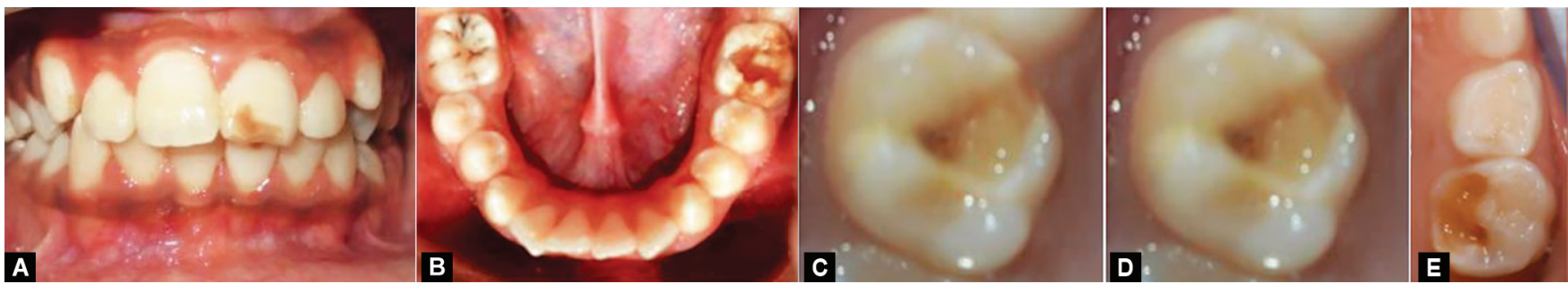

Figs 2A to E: A and B Molar incisor hypomineralization; (C to E) Hypomineralized second primary molars/deciduous molar hypomineralization (HSPM/ DMH)

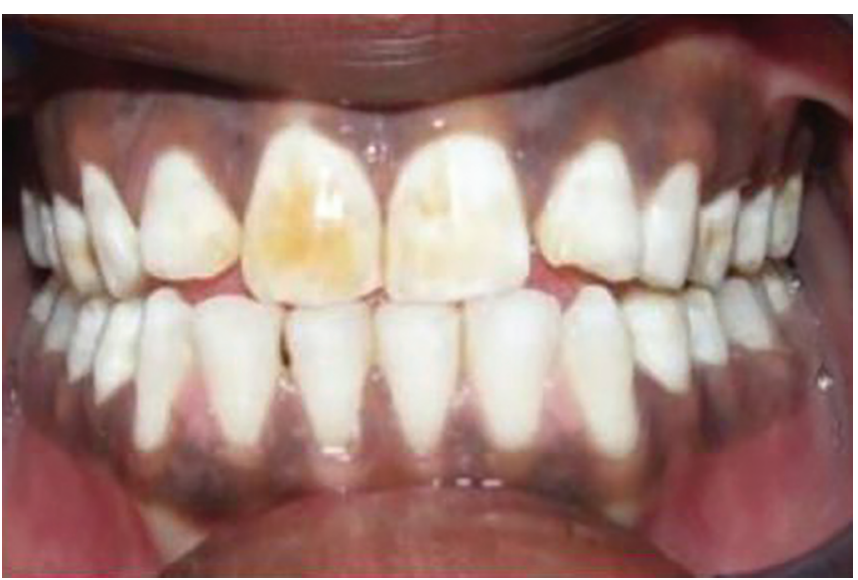

Fig. 3: Dental fluorosis

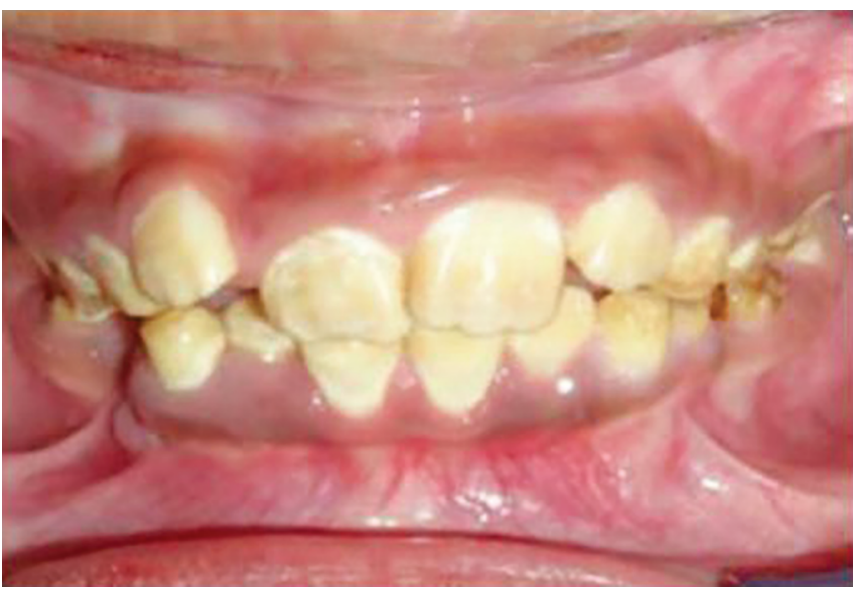

Fig. 4: Amelogenesis imperfecta 
dentist and help establish a dental home for these children for more predictable, preventive and rehabilitative treatment outcomes.

\section{Management of DDE}

The successful management of teeth with DDE is aimed at achieving their predictable and sustainable rehabilitation. It poses a unique challenge to the pediatric dentist owing to the associated hypersensitivity, rapid caries development, poor bond strength of restorations to affected teeth, all further compounded by the limited cooperation of a young child. Interception should begin as early as possible. To prevent or avoid the loss of coronal tooth structure, or early pulp exposure and from the untreated consequences, it is necessary to cover severely affected teeth with stainless steel crowns or other aesthetic full-coverage crowns like preformed zirconia crowns. Pulp therapy should be rendered wherever it is required. When the children reach adulthood, the interim restorations may be replaced with more definitive long-lasting materials as cast metal, lithium disilicate, or zirconia. A brief description of the management of DDE has been shown (Fig. 6).

\section{Discussion}

The genetic and epigenetic factors can influence the tooth development process and limits to isolated teeth which submit nongenetic, environmental factors related to the past medical history could be the cause. Moreover, no specific mutation has yet been identified. The phenotype varies according to its severity. Molecular control of tooth formation is known to involve a number of pathways and evidence indicates that hedgehog and fibroblast growth factor are both important in the regulation of Hertwig's Epithelial Root Sheath. ${ }^{13}$

Early childhood systemic illnesses up to three or four years of life have also been thoroughly investigated. A critical review on etiology has suggested that pre, peri, and neonatal problems increase the prevalence of DDE, however, a significant number of further investigations are needed.

According to published studies seeking possible risk factors, low socioeconomic status, respiratory infections, exposure to cigarette smoking, asthma, otitis media, urinary tract infection, chickenpox, and early life health problems have also been suggested to be associated with DDE. ${ }^{14-16}$ However, these results have always been challenged. For example, amoxicillin has been reported to significantly increase the probability of DDE but such an effect was not found among a random sample of Western Australian children. ${ }^{17-19}$ Similar conflicting results have also been

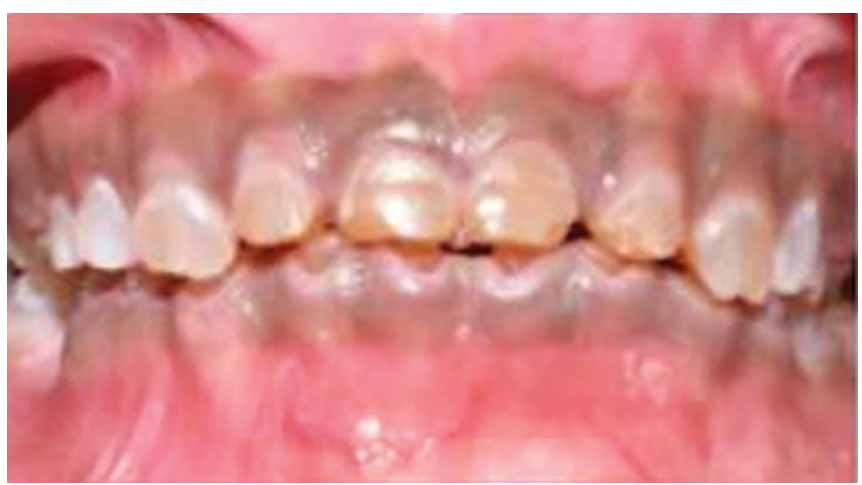

Fig. 5: Dentinogenesis imperfecta reported for the impacts of otitis media, chickenpox, and maternal factors. Furthermore, studies from New Zealand failed to correlate any early life health problems and the occurrence of DDE in the permanent dentition. ${ }^{20}$

The DDE can result from environmental stressors such as anticancer therapy, that occurs during the critical tooth developmental periods. ${ }^{21,22}$ Phenotypes of dental defects arising due to environmental stressors like anticancer therapy and severe infections are usually generalized involving all the teeth developing at the time of the exposure to these factors. Brin et al. reported the agenesis of mandibular premolar root formation associated with hereditary renal disease. ${ }^{23}$ There are other conditions also where generalized root formation gets affected as seen in Rothmund-Thomson syndrome.

It has been found that several systemic conditions in the early stages of life affect the specific cell lines involved in tooth development and this usually occurs during crown formation, and often becomes quite devastating as the cells transition from crown to root formation.

According to the multivariate logistic regression model, a significant association between jaundice and DDE was reported with a correlation coefficient of 0.3 . However, it was not considered as a strong association. Jaundice, which is also known as hyperbilirubinemia, can be detected when the total serum level of bilirubin exceeds $5 \mathrm{mg}$ per $\mathrm{dL}$, a condition that is not uncommon among newborns. ${ }^{24,25}$ Another medical risk factor that could have a significant effect on tooth development is a perinatal factor, that is, Mode of delivery. Cesarean sections are associated with short- and long-term risk which can extend many years beyond the current delivery and affect the health of the woman, her child, and future pregnancies. Although the medium- and long-term consequences of C-section delivery, as opposed to vaginal delivery, on infant health are unclear, epidemiological studies suggest that it is associated with a higher risk of developing asthma, food allergy, type 1 diabetes, and obesity during infancy.

Spinal anesthesia is the most common anesthetic technique used for cesarean delivery which can lead to maternal hypotension which may further have serious consequences for the mother and unborn child later. Cesarean-section can cause a delay in postnatal establishment of gut microbiota and subsequent alterations to the maturation of the mucosal immune system. Children born by elective cesarean section have an increased risk of respiratory morbidity $(\mathrm{OR}=1.9 ; \mathrm{Cl} 1.2-3)$ compared with children born by vaginal delivery or by emergency cesarean. ${ }^{23}$ According to Lygidakis et al. who have conducted a retrospective study, reported that a long/complicated birth (9.4\%), delivery by cesarean section (25.5\%), premature birth $8 \%$, twin birth (16.6\%), and hemorrhage with detachment during delivery $(0.5 \%)$ were most frequently encountered medical problems seen in children diagnosed DDE. ${ }^{26}$ Broad terms used in the studies, such as "complications at birth," "complicated vaginal delivery," and "oxygenation without intubation" were likely to be associated with a degree of hypoxia, which could disrupt the amelogenesis process and result in DDE. Perinatal hypoxia is commonly assessed by the five domains, Appearance, Pulse, Grimace, Activity, and Respiration (AGPAR) score. In general, an AGPAR score is used to quickly assess the health of a newborn child with a score of zero, one or two given to each of the five domains. ${ }^{27}$ AGPAR scores of $=7$ (normal oxygenation), 4-6 (fairly low oxygenation), and $=3$ (critically low oxygenation) given after 1 minute are widely accepted as a criterion to assess oxygenation. ${ }^{28,29}$ Garot et al. identified perinatal hypoxia related 


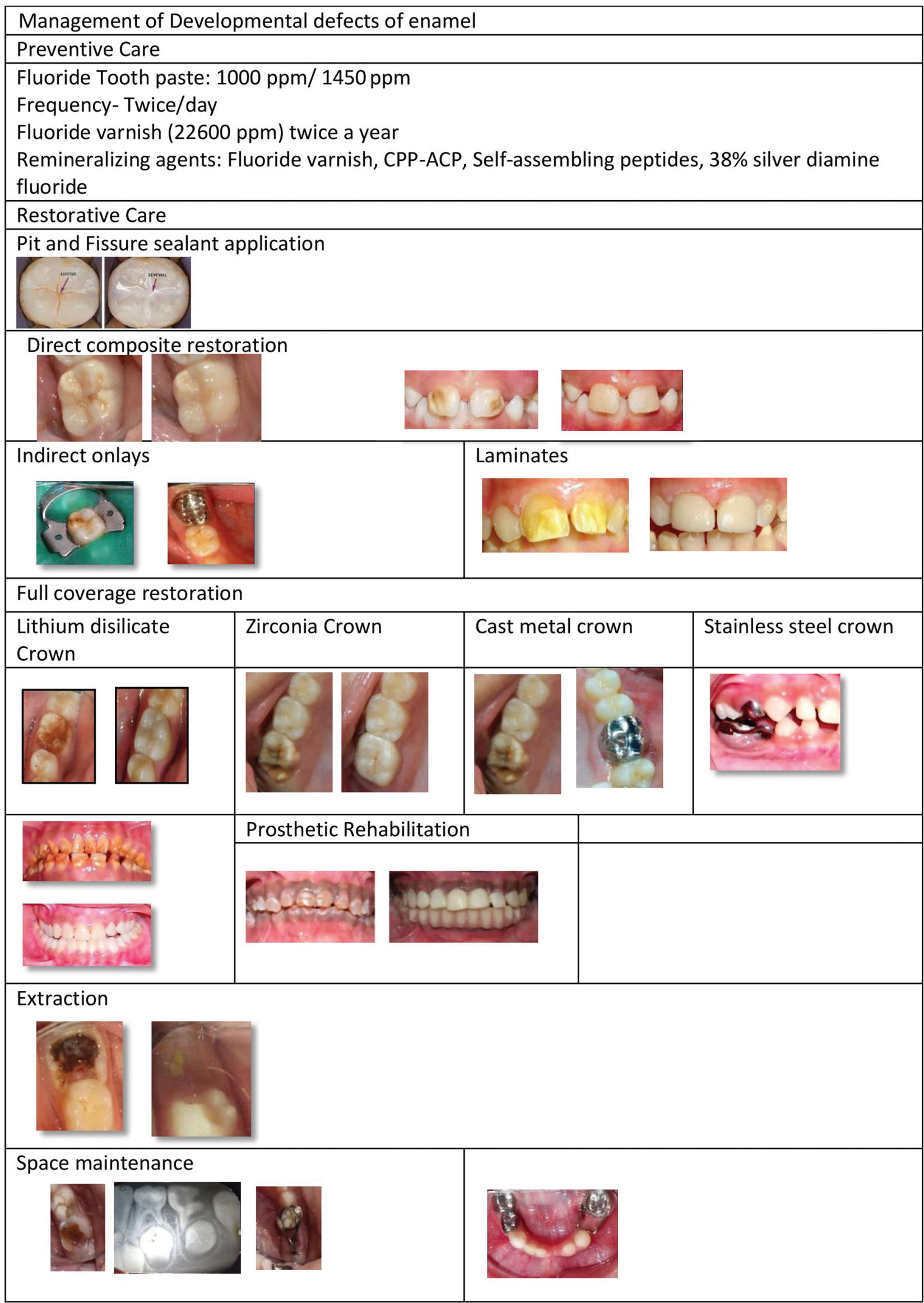

Fig. 6: Management of developmental defects of enamel 
to DDE when an APGAR score of $<7$ was recorded after the first minute from birth. ${ }^{30}$

According to Tawana Pascon et al., gestational diabetes has been independently associated with DDE particularly those manifesting as demarcated opacities. ${ }^{31}$ The deciduous dentition has shown a significantly higher propensity for involvement than the permanent dentition. Vucic $S$ et al. conducted a population-based generation $\mathrm{R}$ study and observed that there was no significant association between maternal thyroid function and the dental development score of the child. ${ }^{32}$ However, thyroid peroxidase (TPOAb) positive mothers had children with lower dental development score compared to TPOAb- negative mothers, which suggests that thyroid hormone is involved in the maturation of teeth from the early stages of life.

A retrospective analysis of risk factors by Wright et al., identified a variety of medical conditions associated with MRIM, the most common being neurologic. ${ }^{12}$ However, the root malformations were limited to isolated teeth suggesting that a non-genetic, environmental factor related to past medical history could be the cause. Thus, the authors suggested a possible epigenetic association which needs further investigations. ${ }^{32}$ Based on the literature, the most significant systemic disorders associated with MRIM are central nervous system related diseases at around 1-2 years of age, however, it is not absolute. Meningomyelocele, a nonlethal congenital malformation in neural deficits spectrum, and spina bifida, caused by incomplete closure of vertebral column during embryogenesis, have been reported as some of the significant risk factors. ${ }^{33}$ Other risk factors that have been mentioned are chronic renal failure, sacral dimple, urinary tract infections, meningitis, early childhood illness, preterm birth, neonatal jaundice etc. Besides CNS related diseases, it was also found in cases treated with antibiotics both intravenously and orally in the first 2 years of life. ${ }^{34}$

Observational studies provide the only means of assessing the association between suspected etiological factors and DDE in the population because randomization is not possible. However, without randomization, the confounders may mask the true relationship between the exposure and outcome. Overall, there are three major problems with the studies dealing with the etiology of DDE. The first is being the lack of adjustment for confounding factors. This is generally overcome through various statistical methods, most commonly multiple regression, which is almost mandatory in such studies. The second is that most of the reported retrospective studies rely on parent recall. There is strong evidence to indicate that mothers accurately recall perinatal factors such as gestational age, birthweight, and mode of delivery, even many years after the events. ${ }^{35}$ However, some aspects of maternal health during pregnancy, recall of breastfeeding duration, child illness, and medication use are less likely to be reliable. ${ }^{36,37}$

Further studies with longer follow-up and through detailed documentation of medical record which is highly desirable to better understand the pathogenesis, etiology, and clinical behavior of various types of DDE.

\section{Conclusion}

The peri-, pre-, and postnatal aetiological factors can produce different defects at different stages of tooth development. Enamel defects may also result from a combination of factors that increases the risk for tooth wear and erosion which further affects the oral health-related quality of life negatively. Risk assessment and age-appropriate anticipatory guidance needs to be practiced for timely management, which is strengthened by endorsing the coordination between pediatric dentist and pediatricians.

\section{ORCID}

Mrinalini Rathore ๑ https://orcid.org/0000-0001-9137-9885

\section{References}

1. Bei M. Molecular genetics of tooth development. Curr Opin Genet Dev 2009;19(5):504-510. DOI: 10.1016/j.gde.2009.09.002

2. Crombie F, Manton D. Aetiology of molar-incisor hypomineralization: a critical review. Int J Paediatr Dent 2009;19(2):73-83. DOI: $10.1111 / j .1365-263 X .2008 .00966 . x$

3. Jalevik B, Klingberg GA. Dental treatment, dental fear and behaviour management problems in children with severe enamel hypomineralization of their permanent first molars. Int J Paediatr Dent 2002;12(1):24-32.

4. Alaluusua S. Aetiology of molar-incisor hypomineralisation: a systematic review. Eur Arch Paediatr Dent 2010;11(2):53-58. DOI: $10.1007 / \mathrm{BF} 03262713$

5. MacDougall M, Simmons D, Luan X, et al. Dentin phosphoprotein and dentin sialoprotein are cleavage products expressed from a single transcript coded by a gene on human chromosome 4 . Dentin phosphoprotein DNA sequence determination. J Biol Chem 1997;272(2):835-842. DOI: 10.1074/jbc.272.2.835.

6. Witkop CJ, Rao S. Inherited Defects in Tooth Structure. Baltimore, Williams and Wilkins; 1971:153

7. Kim JW, Simmer JP. Hereditary dentin defects. J Dent Res 2007;86(5):392-399. DOI: 10.1177/154405910708600502

8. Witkop CJ. Hereditary defects in enamel and dentin. Acta Genet Stat Med 1957;7(1):236-239. DOI: 10.1159/000150974

9. Bonaventure J, Stanescu R, Stanescu V, et al. Type II collagen defect in two sibs with the Goldblatt syndrome, a chondrodysplasia with dentinogenesis imperfecta, and joint laxity. Am J Med Genet A 1992;44(6):738-753. DOI: 10.1002/ajmg.1320440607

10. Witt CVA, Hirt T, Rutz G, et al. Root malformation associated with a cervical mineralized diaphragm - a distinct form of tooth abnormality? Oral Surg Oral Med Oral Pathol Oral Radiol 2014;117(4):e311-e319. DOI: 10.1016/j.00oo.2013.06.030

11. Lee HS, Kim SH, Kim SO, et al. A new type of dental anomaly: molarincisor malformation (MIM). Oral Surg Oral Med Oral Pathol Oral Radiol 2014;118(1):101-109.e3. DOI: 10.1016/j.0ooo.2014.03.014

12. Wright JT, Curran A, Kim KJ, et al. Molar root-incisor malformation: considerations of diverse developmental and etiologic factors. Oral Surg Oral Med Oral Pathol Oral Radiol 2016;121(2):164-172. DOI: 10.1016/j.0000.2015.08.024

13. Huang XF, Chai Y. Molecular regulatory mechanism of tooth root development. Int J Oral Sci 2012;4(4):177-181. DOI: 10.1038/ ijos.2012.61

14. Ford D, Seow WK, Kazoullis S, et al. A controlled study of risk factors for enamel hypoplasia in the permanent dentition. Pediatr Dent 2009;31(5):382-388.

15. Tapias-Ledesma MA, Jiménez R, Lamas F, et al. Factors associated with first molar dental enamel defects: a multivariate epidemiological approach. ASDC J Dent Child 2003;70(3):215-220.

16. Suckling GW, Herbison GP, Brown RH. Etiological factors influencing the prevalence of developmental defects of dental enamel in nine-year-old New Zealand children participating in a health and development study. J Dent Res 1987;66(9):1466-1469. DOI: $10.1177 / 00220345870660091101$

17. Hong L, Levy SM, Warren JJ, et al. Association of amoxicillin use during early childhood with developmental tooth enamel defects. Arch Pediatr Adolesc Med 2005;159(10):943-948. DOI: 10.1001/ archpedi.159.10.943

18. Whatling R, Fearne J. Molar incisor hypomineralization: a study of aetiological factors in a group of UK children. Int J Paediatr Dent 2008;18(3):155-162. DOI: 10.1111/j.1365-263X.2007.00901.x 
19. Arrow P. Risk factors in the occurrence of enamel defects of the first permanent molars among schoolchildren in Western Australia. Community Dent Oral Epidemiol 2009;37(5):405-415. DOI: 10.1111/j.1600-0528.2009.00480.x

20. Suckling G, Pearce E. Developmental defects of enamel in a group of NewZealand children:their prevalenceand some associated etiological factors. Community Dent Oral Epidemiol 1984;12(3):177-184. DOI: 10.1111/j.1600-0528.1984.tb01434.x

21. Holta P, Alaluusua S, Saarinen-Pihkala UM, et al. Longterm adverse effects on dentition in children with poor risk neuroblastoma treated with high dose chemotherapy and autologous stem cell transplantation with or without total body irradiation. Bone Marrow Transplant 2002;29(2):121-127. DOI: 10.1038/sj.bmt.1703330

22. Cubukcu CE, Sevinir B, Ercan I. Disturbed dental development of permanent teeth in children with solid tumors and lymphomas. Pediatr Blood Cancer 2012;58(1):80-84. DOI: 10.1002/pbc.22902

23. Brin I, Zilberman Y, Galili D, et al. Eruption of rootless teeth in congenital renal disease. Oral Surg Oral Med Oral Pathol 1985;60(1):61-64. DOI: 10.1016/0030-4220(85)90217-8

24. Lauer BJ, Spector ND. Hyperbilirubinemia in the newborn. Pediatr Rev 2011;32(8):341-349. DOI: 10.1542/pir.32-8-341

25. Wan A, Daud SM, Teh S, et al. Management of neonatal jaundice in primary care. Malays Fam Physician 2016;11(2-3):16-19.

26. Lygidakis NA, Dimou G, Marinou D. Molar-incisor-hypomineralisation (MIH). A retrospective clinical study in Greek children. II. Possible medical aetiological factors. Eur Arch Paediatr Dent 2008;9(4):207-217. DOI: 10.1007/BF03262637

27. Apgar V. Proposal for a new method of evaluation of the newborn infant. Curr Res Anesth Analg 1953;32(4):260-267.

28. Casey BM, McIntire DD, Leveno KJ. The continuing value of the Apgar score for the assessment of newborn infants. N Engl J Med 2001;344(7):467-471. DOI: 10.1056/NEJM200102153440701
29. Finster M, Wood M. The Apgar score has survived the test of time. Anesthesiology 2005;102(4):855-857. DOI: 10.1097/00000542200504000-00022

30. Pascon T, Barbosa AMP, Cordeiro RCL, et al. Prenatal exposure to gestational diabetes mellitus increases developmental defects in the enamel of offspring. PLoS One 2019 14(2):e0211771. DOI: 10.1371/ journal.pone.0211771

31. Vucic S, Korevaar TIM, Dhamo B, et al. Thyroid function during early life and dental development. J Dent Res 2017;96(9):1020-1026. DOI: 10.1177/0022034517708551

32. Yokohama-Tamaki T, Ohshima H, Fujjiwara N, et al. Cessation of Fgf10 signalling resulting in a defective dental epithelial stem cell compartment leads to the transition from crown to root formation. Development 2006:133(7):1359-1366. DOI: 10.1242/dev.02307

33. Haq IZ, Akmal S, Chandler CL, et al. Review of practices in myelomeningocoele repair at King's College hospital, London. Br J Neurosurg 2012;26(6):851-855.

34. Luder HU. Malformation of the tooth root in humans. Front Physiol 2015;6:307. DOI: 10.3389/fphys.2015.00307

35. Rice F, Lewis A, Harold G, et al. Agreement between maternal report and antenatal records for a range of pre and perinatal factors: the influence of maternal and child characteristics. Early Hum Dev 2007;83(8):497-504. DOI: 10.1016/j.earlhumdev.2006.09.015

36. Liu J, Tuvblad C, Li L, et al. Medical record validation of maternal recall of pregnancy and birth events from a twin cohort. Twin Res Hum Genet 2013;16(4):845-860. DOI: 10.1017/thg.2013.31

37. Tienboon P, Rutishauser IH, Wahlqvist ML. Maternal recall of infant feeding practices after an interval of 14 to $15 y$ ears. Aust J Nutr Diet 1994;51(1):25-27. 